Birlesik Dünya Arastırma

BD-CENTER

Innovasyon ve Yayınılık Merkezi

\section{Global Journal of Foreign \\ Language Teaching}

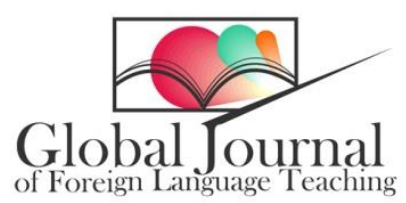

Volume 10, Issue 3, (2020) 198-207

www.gjflt.eu

\title{
BSSI-3 Spoken language, reading-writing forms: Validity and reliability study
}

Fatma Ülkü Yıldız a*, Alaeddin Keykubat Campus, Selcuk University Rectorate, Akademi Mah, Yeni Istanbul Cad. No: 369, 42130 Seljuk-Konya, Turkey https://orcid.org/0000-0002-1164-515X

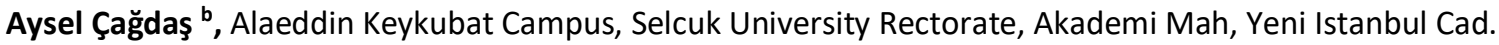
No: 369, 42130 Seljuk-Konya, Turkey https://orcid.org/0000-0002-1082-3815

Gökhan Kayılı c, Alaeddin Keykubat Campus, Selcuk University Rectorate, Akademi Mah, Yeni Istanbul Cad. No: 369, 42130 Seljuk-Konya, Turkey https://orcid.org/0000-0001-7959-4128

\section{Suggested Citation:}

Yıldız, F. Ü., Çağdaş, A. \& Kayıılı G. (2020). BSSI-3 Spoken language, reading-writing forms: Validity and reliability study. Global Journal of Foreign Language Teaching. 10(3), 198-207. https://doi.org/10.18844/gjflt.v10i3.5074

Received April 11, 2020; revised June 28, 2020; accepted August 14, 2020.

Selection and peer review under responsibility of Assoc Prof Dr. Ali Rahimi, Bangkok University, Thailand.

${ }^{\circledR} 2020$ Birlesik Dunya Yenilik Arastirma ve Yayincilik Merkezi. All rights reserved.

\begin{abstract}
This study was conducted to determine whether the 'Spoken Language' and 'Reading-Writing' forms of the Basic School Skills Inventory-3 Edition had validity and reliability characteristics acceptable for Turkish children aged 48-72 months old. The sample of the study included 244 children selected through the simple random sampling method. Exploratory factor analysis (principal components analysis) was conducted to determine the construct validity of the tests. The fit index was tested with maximum likelihood confirmatory factor analysis. Reliability of the test was ensured using internal consistency coefficient and split-half test. Cronbach's alpha reliability coefficients of the forms were calculated to be 0.95 and 0.97 . Analysed for its adaptation into Turkish, the BSSI-3 Spoken Language and Reading-Writing forms were a valid and reliable assessment tool for Turkish children aged 48-72 months old.
\end{abstract}

Keywords: Spoken language, reading-writing, validity and reliability.

* ADDRESS FOR CORRESPONDENCE: Fatma Ulku Yildiz, Alaeddin Keykubat Campus, Selcuk University Rectorate, Akademi Mah, Yeni Istanbul Cad. No: 369, 42130 Seljuk-Konya, Turkey. E-mail address: fulkuyildiz@gmail.com 
Yıldız, F. Ü., Çağdaş, A. \& Kayılı G. (2020). BSSI-3 Spoken language, reading-writing forms: Validity and reliability study. Global Journal of Foreign Language Teaching. 10(3), 198-207. https://doi.org/10.18844/gjflt.v10i3.5074

\section{Introduction}

Learning is one of the most basic needs for children. Infancy and early childhood (e.g., adolescence) mark the fastest developmental periods of children. The periods of rapid development also include critical periods for learning. Infancy and early childhood in human life are among the most sensitive periods for language development (Alanazi \& Thompson, 2019; Senemoglu, 2013). Montessori named certain periods during which a particular ability in children develops rapidly as sensitive periods (Montessori, 2015a). The child shows no fatigue during an activity occurring in a sensitive period. On the contrary, he appears to be self-satisfied, calm or even rested (Standing, 1998, p. 122). A sensitive period is the developmental period where certain external influences (positive or negative) promote maximum positive development or lead to negative (detrimental) consequences (Elyildirim, 2019). The acquisition of speech also depends on such a sensitive stage (Kasten, 2017, p. 28). Once the sensitive period has been left behind, it is almost impossible to create a new development related to the area in question. Language development is a mysterious phenomenon. Children go through stages where they focus on certain abilities, and their minds work differently than ours. These activities, carried out in a modest silence, provide children with skills (such as language, speech, reading and writing) that will make them happy for a lifetime (Montessori, 1997, p. 52).Language reflects the mind. It is through this lovely flame that burns without consuming that the work of creating the mental world of man takes place (Montessori, 2015b, p.42).

The ability to communicate through language is one of the important factors that ensures the quality and continuous progress of human life. Communication is a fundamental skill required for the interaction among people of all ages (Dere Ciftci, 2013, p.7). People use language to express and teach their thoughts, feelings, attitudes, beliefs and values, and to transfer information about perceived, experienced events and their cultural richness. The language also reflects different attitudes such as asking questions, giving orders, making requests and solving common problems through cooperation which is achieved by communication (Aral \& Baran, 2011, p. 164).Language plays an important role in a child's learning. It is known that spoken language, written language and reading contribute to language and intellectual development. The transfer of knowledge from one generation to another also occurs by means of written and verbal communication (Polk Lillard, 2013, p.47).

Language development is related to many cognitive skills, including the ability to speak, distinguishing and remembering sounds, exploring rules by listening to the language, combining concepts with sound patterns, controlling the muscles that are essential to making sounds and transforming thoughts into words (Gander \&Gardiner, 2017; Mekkaoui \& Mouhadjer, 2019). It is of the utmost importance to recognise the strengths and weaknesses of children in early childhood. Teachers' judgments, attitudes and behaviours about the child are a key factor in children's school learning. Decisions and assessments by teachers regarding student ability are also used by schools to guide a wide variety of identification, placement and learning topics on a daily basis. When making these decisions, it is necessary to work based on a standard and a certificate. If the development of children is to be monitored based on a certificate, it is appropriate for the teachers, who are the closest to the children in the institutional structure, to make these assessments (Hammill, Leigh, Pearson \& Maddox, 1998).

Main function of assessment tools is to determine an individual's position on psychological dimension in view of their measurable properties according to their responses (reactions) to a certain number of test items (stimuli) selected based on specific techniques. (Tezbasaran, 2008). Scales can be used for various purposes following their standardisation with ensured validity and reliability. These purposes cover sorting out children's early learning skills, identifying individual strengths and weaknesses, identifying the degree of risk for failure and finding out if there occurs an increase or decrease in the development of children due to any effect (such as time, a new education programme, experimental practices). Learning models and learning areas differ from culture to culture. This validity and reliability study was needed to identify and eliminate the differences resulting from culture and 
Yıldız, F. Ü., Çağdaş, A. \& Kayılı G. (2020). BSSI-3 Spoken language, reading-writing forms: Validity and reliability study. Global Journal of Foreign Language Teaching. 10(3), 198-207. https://doi.org/10.18844/gjflt.v10i3.5074

learning in the 'Spoken Language' and 'Reading-Writing' subtests of the BSSI-3 developed within another culture for 4-6-year-oldchildren (Namaziandost, Imani \& Ziafar, 2020).

This study was undertaken to test whether the 'Spoken Language' and 'Reading-Writing' forms of the BSSI-3 have validity and reliability in measuring skills development of Turkish children.

\section{Method}

\subsection{Second-order head}

Based on a general survey design which aims to describe a present situation as it exists, the current study was undertaken for the purpose of scale adaptation and validity-reliability study.

\subsection{Participants}

The data for this study were collected from children attending an applied kindergarten affiliated to a university and 5 public preschools from the central districts of Konya province (Meram, Selcuk, Karatay) during the 2018-2019 school year. The schools included in the study were selected by means of random cluster sampling. A total of 244 children between the ages of 4 and 6 years (48-72 months) were included in the study; of these, 123 were girls (50.4\%) and 121 were boys (49.6). 48 of the children were 4 years old(19.7\%), 96 were 5 -year old(39.3\%) and 100 were 6 years old(41.0\%) (Wariyo, 2019).

\section{Data collection tools}

\subsection{Basic school skills inventory}

It was first developed by teachers in 1971 to assess the development, behaviour and school readiness of 4-5-year-old children. Diagnostic and screening models were prepared in 1981 . Created in 1992 by Hammill, Leigh, Pearson and Maddox (1988), the BSSI-3 Edition consists of 6 subtests and a total of 137 items which can be administered individually to 4-8-year-olds. The subtests cover the following skill areas: Spoken Language, Reading, Writing, Mathematics, Classroom Behaviour and Daily Living Skills. In 2017, the adaptation and validity-reliability study of the three subtests - Mathematics, Classroom Behaviour and Daily Living Skills - were conducted for Turkish children aged 4-6 years. As a result of the study, mathematics was reduced to 20 items, classroom behaviour to 22 items and daily living skills to 23 items (Yildiz, Cagdas \& Kayili, 2017).

The aim of this study is to establish the validity and reliability of the three subtests of the Basic School Skills Inventory-3-Spoken Language (26 items), Reading ( 23 items)and Writing (20 items) - for Turkish children aged 4-6 years old. Based on expert views, the Spoken Language was reduced from 26 to 24 items, Reading from 23 to 20 items and Writing from 20 to 11 items. The number of the test items within Spoken Language, Reading and Writing subtests, which originally consisted of 89 items in total, was reduced to 54 items following the expert's views.

The BSSI-3 is structured based on a 4-point Likert scale, with 0-Does not perform, 1-Beginning to perform, 2-Performs most of the time and 3-Performance indicates mastery.

Validity and reliability studies were conducted in more than ten states of the United States. Reliability coefficient was calculated to be 0.90 .

The current study was carried out to test whether the 'Spoken Language' and 'Reading-Writing' subtests of the BSSI-3 have validity and reliability characteristics acceptable for Turkish children. 
Yıldız, F. Ü., Çağdaş, A. \& Kayılı G. (2020). BSSI-3 Spoken language, reading-writing forms: Validity and reliability study. Global Journal of Foreign Language Teaching. 10(3), 198-207. https://doi.org/10.18844/gjflt.v10i3.5074

\subsubsection{Basic school skills inventory 3 - spoken language}

The test items included in the spoken language measure the child's ability to communicate orally. Oral language is language-oriented, as it is an integral part of many areas of the child's school performance in all the BSSI-3 subtests. Nevertheless, the areas contained in the spoken language phonology (e.g., speech sounds), morphology (e.g., tense and the correct use of plural endings), syntax (e.g., asking a question using correct sentence structure,) and semantics (using age appropriate vocabulary) - are related to the linguistic skills. In addition, the pragmatic aspect of the language (e.g., the use of language to communicate for various purposes) was also included in the tests.

\subsubsection{Basic school skills inventory 3 - reading-writing}

The Reading subtest measures the child's print knowledge which encompasses letters, words, sentences and paragraphs. A wide range of reading skills are evaluated, including letter knowledge, sound-symbol relationship, sight-word recognition, use of grammatical sign systems, guessing words from the context and the ability to comprehend main ideas in stories. Skills such as holding a book the right way to read are also assessed. It is not intended to represent a set of distinct and isolated skills related to reading in the subtest; instead, it is intended to reflect a compilation of abilities, knowledge and behaviours that are quite useful in developing reading comprehension. The writing subtest measures the abilities and skills directly involved in the writing of letters, words and sentences. As this subtest originally consisting of 20 items is arranged according to children aged 4-6 years rather than 4-8 years, Reading and Writing subtests are administered together and cover 11 writing items. Items include writing words and sentences, spelling, correct capitalisation and punctuation, writing grammatically and linguistically correct sentences, central theme or subject and communicating with others through meaningful and purposeful writing. This test does not apply to children under 5 years of age (Hamill et al., 1998, p. 6).

\section{Basic school skills inventory-3 spoken language and reading-writing forms: Turkish adaptation and preliminary study}

The Turkish adaptation of the BSSI-3 Spoken Language and Reading-Writing forms was started by translating the test items from English to Turkish by researchers. It was later translated back into English by an expert in English Language and Literature using the backward translation method and compared to the original test items. It was observed that there was a unity in expressions and meaning between the items translated into Turkish and the original ones. Eight academics working in the field of Child Development and Education were then requested to evaluate the suitability of the test for 4-6-year-old Turkish children and make recommendations. Based on the expert's views, the BSSI-3 Spoken Language and Reading-Writing Forms were accepted to have content validity. The test was also administered to a group of 12 teachers and the test items were checked by teachers to see if they were understandable. It was seen that all the teachers participating could understand all the items contained in the draft forms, and thus the draft forms were made ready for implementation.

\section{Data analysis}

The validity of the BSSI-3 Spoken Language and Reading-Writing Forms was evaluated using content and construct validity. Test-retest and split-half methodology were used for there liability of theBSSI-3 Spoken Language and Reading-Writing Forms. Research data were analysed using Statistical Package for the Social Sciences 22.0 and LISREL 8.80 data analysis package programme. 
Yıldız, F. Ü., Çağdaş, A. \& Kayılı G. (2020). BSSI-3 Spoken language, reading-writing forms: Validity and reliability study. Global Journal of Foreign Language Teaching. 10(3), 198-207. https://doi.org/10.18844/gjflt.v10i3.5074

\section{Results and conclusion}

\subsection{Validity of the BSSI-3 spoken language and reading-writing forms}

Validity refers to how accurately a data collection instrument measures what it is intended to measure. Different classifications can be used for validity studies. The most widely used methods in these classifications - content validity and construct validity - were included in the present study (Buyukozturk, 2013).

\subsection{Content validity of the BSSI-3 spoken language and reading-writing forms}

Content validity is the evaluation of whether the items in the instrument are appropriate for the purpose of measurement and whether they represent the area or skill to be measured (Karasar, 2013). For the content validity of this study, the test items were evaluated by eight academics working in the field of Child Development and Education and they all verified the appropriateness of the test items and offered some recommendations. Considering these recommendations, some modifications were made, yet no change was made in the number of test items. In addition, necessary corrections were made regarding language clarity to reach the final form of the tests, ensuring the content validity.

\subsection{Construct validity of the BSSI-3 spoken language and reading-writing forms}

The construct validity indicates whether the items of a test or instrument measure the behaviours or skills they are intended to measure, or the degree to which test items measure the behaviours or skills accurately. Exploratory factor analysis technique was used to analyse the construct validity of the Spoken language and Reading-Writing Forms of the BSSI-3. Kaiser-Meyer-Olkin (KMO) coefficient and Bartlett's sphericity test were used to decide whether the data collected were suitable for factor analysis. The value of the KMO coefficient indicates whether the sample size fits and is adequate for the factor analysis. The data provide good fit for the factor analysis when the KMO coefficient is as near as 1 . The value of the KMO coefficient for the BSSI-3 Spoken Language Form was calculated to be 0.951 , and Bartlett's sphericity $\left(\chi^{2}=5,678.551 ; p<0.01\right)$ and chi-square tests were found to be significant. For the BSSI-3 Reading-Writing Form, KMO coefficient value was 0.923, and Bartlett's sphericity $\left(\chi^{2}=6,681.564 ; p<0.01\right)$ and chi-square tests were found to be significant. In line with the results reached, it was seen that the data collected within the scope of the study were suitable for factor analysis. Principal components factor analysis was performed to reveal structures called factors or components. The results of the analysis showed that there was only one factor greater than 1 for each form and it would be correct to evaluate both separate forms of the inventory in a single dimension only.

Table 1. Results of exploratory factor analysis for the BSSI-3 spoken language

\begin{tabular}{clc}
\hline Number & Test items & Factor loading \\
\hline 1 & Uses grammatically correct sentences when speaking. & 0.82 \\
2 & Uses age-appropriate vocabulary. & 0.85 \\
3 & Uses personal pronouns (e.g., l, you, she) correctly in sentences. & 0.84 \\
4 & Answers who, what, when, where and why questions . & 0.82 \\
5 & Uses correctly the prepositions of place (e.g., in, under, next to) in a sentence. & 0.81 \\
6 & Pronounces correctly the words s/he uses. & 0.75 \\
7 & Sings children's songs or recites nursery rhymes and poems s/he has learned in the & 0.74 \\
8 & classroom. & 0.81 \\
9 & Uses possessive pronouns correctly in a sentence (e.g., his, mine, your) & 0.80 \\
10 & Describes the contents of the images accurately. & 0.80 \\
11 & Answers the questions correctly after hearing a story. & 0.83
\end{tabular}


Yıldız, F. Ü., Çağdaş, A. \& Kayılı G. (2020). BSSI-3 Spoken language, reading-writing forms: Validity and reliability study. Global Journal of Foreign Language Teaching. 10(3), 198-207. https://doi.org/10.18844/gjflt.v10i3.5074

\begin{tabular}{lll}
12 & Uses the past, present and future tense suffixes correctly in the sentence. & 0.73 \\
13 & Ask questions in appropriate sentence structures. & 0.77 \\
14 & Uses plural suffixes (e.g., cat carriages, boys) correctly. & 0.79 \\
15 & After hearing a story, retells the four or more events in the story using the & 0.80 \\
& appropriate sequence. & 0.80 \\
16 & Combines sentences using conjunctions. & 0.69 \\
17 & Follows verbal instructions. & 0.74 \\
18 & Starts and maintains conversations with others. & 0.80 \\
19 & Talks about needs or feelings. & 0.73 \\
20 & Ask appropriate questions for situations. & 0.69 \\
21 & Uses language (on a socially acceptable subject) to influence others. & 0.58 \\
22 & Uses language to participate in creative or imaginary events. & 0.66 \\
23 & Effectively expresses his/her ideas when speaking in front of a group. & 0.75 \\
24 & Uses verbal reasoning or problem solving skills. & \\
\hline
\end{tabular}

As can be seen in Table 1, the factor loadings of the items of the BSSI-3 Spoken Language Form range between 0.58 and 0.85 . According to Buyukozturk (2013), the items with a factor loading of 0.30 and higher distinguish individuals well; items with a factor loading between 0.20 and 0.30 can either be removed from the test if necessary or they need to be corrected, and items showing a factor loading lower than 20 should be removed from the test. With reference to these values, all test items can be considered to have a high distinguishing feature. However, no item was removed from the inventory form and the test consisted of 24 items in total. In addition, the total variance rate explained was $61 \%$. This value is suggested to be greater than $50 \%$ in psychological tests.

Confirmatory factor analysis was conducted in order to test the factorial structure of the BSSI3Spoken Language Form. Maximum likelihood confirmatory factor analysis was used to test the fitness index of the Spoken Language Form and eight separate data fitness indices were calculated. These are chi-square $\left(\chi^{2}\right)$, degree of freedom $(S d)$, ratio of chi-square to degree of freedom $\left(\chi^{2} / S d\right)$, root mean square error of approximation (RMSEA), goodness-of-fit index (GFI), adjusted goodness-fit-index (AGFI), comparative fit index (CFI) and non-normed fitness index (NNFI). According to Simsek (2007), these are the most commonly used fit indices. Table 2 shows the results of the confirmatory factor analysis for the BSSI-3 Spoken Language Form.

Table 2. The results of the confirmatory factor analysis for BSSI-3Spoken Language Form

\begin{tabular}{ccccccccc}
\hline Fit indices & $\chi^{2}$ & Sd & $\chi^{2} /$ Sd & RMSEA & GFI & AGFI & CFI & NNFI \\
\hline & $1,245.58$ & 1,198 & 1.039 & 0.024 & 0.96 & 0.88 & 0.96 & 0.96 \\
\hline
\end{tabular}

As can be seen in Table 2, the results of the confirmatory factor analysis are as follows: $\chi^{2}=1.245 .58 ; \mathrm{Sd}=1.198 ; \chi^{2} / \mathrm{Sd}=1.039 ; \mathrm{RMSEA}=0.024 ; \mathrm{GFI}=0.96 ; \mathrm{AGFI}=0.88 ; \mathrm{CFI}=0.96 ;$ and $\mathrm{NNFI}=0.96$. Table 3 shows the results of exploratory factor analysis for the BSSI-3 Reading-Writing test items.

Table 3. The results of the exploratory factor analysis for the BSSI-3 Reading-Writing test items

\begin{tabular}{clc}
\hline Number & \multicolumn{1}{c}{ Test items } & Factor loading \\
\hline 1 & Holds the book in the appropriate position. & 0.72 \\
2 & Understands the concept of letters. & 0.57 \\
3 & Names alphabet letters in the correct order. & 0.50 \\
4 & Recognises lower and upper case letters when shown. & 0.77 \\
5 & Names lowercase consonants when presented randomly. & 0.75 \\
6 & Names uppercase letters when presented randomly. & 0.65 \\
7 & Attempts to read words correctly from left to right. & 0.70 \\
8 & Names the letters of sounds when spoken. & 0.78
\end{tabular}


Yıldız, F. Ü., Çağdaş, A. \& Kayılı G. (2020). BSSI-3 Spoken language, reading-writing forms: Validity and reliability study. Global Journal of Foreign Language Teaching. 10(3), 198-207. https://doi.org/10.18844/gjflt.v10i3.5074

\begin{tabular}{lll}
9 & Makes sounds associated with consonants. & 0.76 \\
10 & Vocalises nonsense words (cal, dod, mip). & 0.55 \\
11 & Has basic vocabulary of at least five words. & 0.49 \\
12 & Expresses the sentences that describe a picture. & 0.40 \\
13 & Predicts unknown or missing words in the content of a text. & 0.43 \\
14 & Answers questions about characters or events after listening to a story accompanied & 0.47 \\
& with pictures. & \\
15 & Describes the main events after listening to a story accompanied with pictures. & 0.42 \\
16 & Predicts the logical end of a story being read. & 0.40 \\
17 & the letters within words. & 0.69 \\
18 & Follows symbols (such as WC). & 0.70 \\
19 & Selects books and independently examines them for fun. & 0.60 \\
20 & Quietly examines books without teacher assistance & 0.61 \\
21 & Writes from left to right. & 0.77 \\
22 & Writes his/her own name without an example provided. & 0.75 \\
23 & Copies a short word from a written example and writes it. & 0.71 \\
24 & Copies a short word from the chalkboard and writes it. & 0.70 \\
25 & Writes single letters when requested (for example, b, h, $\mathrm{m}, \mathrm{t}, \mathrm{a}$, ) & 0.75 \\
26 & Writes his/her surname without an example provided. & 0.63 \\
27 & Writes on the lines. & 0.75 \\
28 & Copiesa sentence from chalkboard to paper. & 0.41 \\
29 & Spells simple words correctly. & 0.79 \\
30 & Knows that the first letter of the sentence will be capitalised and puts a period at the & 0.69 \\
& end of the sentence. & \\
31 & Edits his/her own writings. & 0.80 \\
\hline
\end{tabular}

The data in Table 3 show that the factor loadings of the items of the BSSI-3 Reading-Writing Form range from 0.40 to 0.80 . With reference to these values, all test items can be considered to have a high distinguishing feature. Yet, no item was omitted from the inventory form and the test consisted of 31 items in total. In addition, the total variance rate explained was $64 \%$.

Confirmatory factor analysis was carried out to test the factorial structure of the BSSI-3 ReadingWriting Form. Maximum likelihood confirmatory factor analysis was used to test the fitness index of the Reading-Writing Form and eight separate data fitness indices were calculated. Table 4 shows the results of the confirmatory factor analysis for BSSI-3 Reading-Writing Form.

Confirmatory factor analysis is an extension of exploratory factor analysis that evaluates the underlying structure behind the data. Confirmatory factor analysis is used to test whether there exists a relationship between these factors, which variable is related to which factor, and whether the factors are independent of each other (Ozdamar, 2004).

Table 4. The results of the confirmatory factor analysis for theBSSI-3 Reading-Writing Form

\begin{tabular}{ccccccccc}
\hline Fit Indices & $\chi^{2}$ & Sd & $\chi^{2} /$ Sd & RMSEA & GFI & AGFI & CFI & NNFI \\
\hline & $1,428.71$ & 1,360 & 1.050 & 0.032 & 0.93 & 0.85 & 0.94 & 0.95 \\
\hline
\end{tabular}

As shown in Table 4, the results of the confirmatory factor analysis are as follows: $\chi^{2}=1.428 .71$; $\mathrm{Sd}=1.360 ; \chi^{2} / \mathrm{Sd}=1.050 ; \mathrm{RMSEA}=0.032 ; \mathrm{GFI}=0.93 ; \mathrm{AGFI}=0.85 ; \mathrm{CFI}=0.94$; and $\mathrm{NNFI}=0.95$.

According to Simsek (2007), the acceptable degree of conformity varies according to the index. The ratio of chi-square to the degree of freedom is often used in determining the compatibility of the model. A value of two or less indicates that the model is a good model and a value of five or less indicates that the model has an acceptable goodness-of-fit. It is suggested that an RMSEA value below 0.06 is a good fit for the model, and a value below 0.08 is seen as an acceptable goodness-of-fit (Brown, 2006). Regarding RMSEA, the model indicates a good fit. According to Kline (2010), the GFI, 
CFI and NNFI should be 0.90 or higher. AGFI should be around 0.80 or higher (Anderson \& Gerbing, 1984). According to the results of the confirmatory factor analysis presented in Tables 2 and 4, it can be said the model has an acceptable goodness-of-it. In other words, the results of the confirmatory factor analysis seem to verify that the model shows a good fit.

\subsection{Reliability of the BSSI-3 Spoken Language and Reading-Writing Forms}

Reliability refers to the consistency of individuals' responses to the items of the data collection instrument, indicating the degree of stability of the results. Reliability is related to the degree to which the data collection tool accurately measures the intended quality or skill (Buyukozturk, 2013). Internal consistency reliability and split-half methodology were used for the reliability of the BSSI-3 Spoken Language and Reading-Writing Forms.

\subsection{Internal consistency reliability of the BSSI-3 Spoken Language and Reading-Writing Forms}

The Cronbach's alpha was used to calculate the internal consistency reliability of the BSSI-3 Spoken Language and Reading-Writing Forms. Cronbach's Alpha coefficients calculated for age groups are presented in Table 5.

Table 5. BSSI-3 Spoken Language and Reading-Writing Cronbach's
alpha coefficients for age groups
\begin{tabular}{rrr}
\hline BSSI & Age Cronbach's alpha reliability coefficient \\
\hline Spoken Language4 years & 0.95 \\
5 years & 0.97 \\
6 years & 0.97 \\
Reading-Writing 6 years & 0.95 \\
\hline
\end{tabular}

As seen in Table 5, the reliability coefficient computed for the BSSI-3 Spoken Language Form was 0.95 for 4 -year-olds, 0.97 for 5 -year-olds and 0.97 for 6 -year-olds.For the BSSI-3 Reading-Writing Form, the reliability coefficient administered to 6 -year-olds was found to be 0.97 . For a psychological test, according to Buyukozturk (2013), the Cronbach's alpha reliability coefficient of 0.70 or higher is generally considered adequate for the reliability of the test scores. For Johnson and Christensen (2014), a coefficient of 0.70 or higher is acceptable for reliability. High Cronbach's alpha coefficients of the BSSI-3Spoken Language and Reading-Writing Forms indicate that the test is reliable.

\subsection{Split-half reliability of the BSSI-3Spoken Language and Reading-Writing Forms}

The split-half reliability is calculated by using the Spearman-Brown's formula based on the relationship between the two halves of the data collection tool, divided unbiasedly into two equal halves as odd-numbered and even-numbered or first half-second half (Buyukozturk, 2013; Yavas Celik \& Yavuz, 2020). In order to calculate the test reliability of the BSSI-3Spoken Language and ReadingWriting Forms, the items in each form were divided into two halves and the correlation coefficient was calculated on the basis of age groups using the Spearman-Brown's Formula. The SpearmanBrown's reliability coefficients are given in Table 6.

Table 6. BSSI-3 Spearman-Brown's split-half reliability coefficients for age groups

\begin{tabular}{ccc}
\hline BSSI & Age & Spearman-brown's reliability coefficient \\
\hline Spoken Language & 4 years & 0.82 \\
& 5 years & 0.83 \\
& 6 years & 0.88 \\
Reading-Writing & 6 years & 0.87 \\
\hline
\end{tabular}


As shown in Table 6, Spearman-Brown's split half-test reliability coefficients calculated for the BSSI-3 Spoken Language were 0.82 for 4 -year-olds, 0.83 for 5 -year-olds and 0.88 for 6 -year-olds. For the Reading and Writing Form, the split half-test reliability coefficient was found to be 0.87 . The Spearman-Brown's coefficients verify that the split-half reliability of the test is adequate.

The overall conclusion from this study is that the BSSI-3 Spoken Language and Reading-Writing Forms exhibit sufficient validity and reliability to support its use in measuring children's spoken language and reading-writing skills.

\section{Discussion}

Hamill et al. emphasised that validity and reliability studies of the BSSI-3 have been carried out in different environments and cultures and that it is unnecessary to do this again in any culture (Hamill et al., 1998). Nevertheless, the 'Spoken Language and Reading-Writing subtests' of the BSSI-3, which were prepared for 4-8-year-olds, need validity and reliability studies on the basis of 4-6 years of age in our country.

The language translation was done from English to Turkish and from Turkish to English; eight academics working in the field of child development and education evaluated the test items for content validity. As a result, 'Spoken Language' was reduced from 26 items to 24, 'Reading' from 23 items to 20and 'Writing' from 20 items to 11. The data were provided by children's teachers.

Regarding the content validity, the KMO coefficient close to 1 indicated the data were suitable for the analyses. The KMO coefficient was 0.951 for the Spoken Language and 0.923 for the ReadingWriting Form. Bartlett's sphericity and chi-square tests were found to be significant. The results of the analyses showed that there was only one factor greater than 1 for each form and it would be correct to evaluate both separate forms of the inventory in a single dimension only.

Factor loadings varying between 0.58 and 0.85 for the Spoken Language and 0.40 and 0.80 for the Reading-Writing indicated that test items have a high distinguishing feature. According to the results of the confirmatory factor analysis presented in Tables 2 and 4, it can be suggested that the values obtained for the Spoken Language and Reading-Writing Forms show an acceptable goodness-of-it.

For reliability of the BSSI-3 Spoken Language and Reading-Writing Forms, internal consistency reliability and split-half methodology were used. The results given in Tables 5 and 6 suggest that the BSSI-3 Spoken Language and Reading-Writing Forms are a valid and reliable measurement tool for evaluating the skills of children aged 4-6years.

\section{References}

Alanazi, K. \& Thompson, C. (2019). Using social networking technologies to promote language socialisation: English as foreign language teachers' perceptions in Saudi Arabia. Global Journal of Foreign Language Teaching, 9(3), 122-136. doi:10.18844/gjflt.v9i3.4129

Anderson, J. C. \& Gerbing, D. W. (1984). The effect of sampling error on convergence, impropersolutions, and goodness-of-fit indices for maximum likelihood comfirmatory factor analysis. Psychometrika, 49, 155-173.

Aral, N. \& Baran G. (2011). Cocuk gelisimi (Child development).Istanbul, Turkey: YA-PA Yayin A.S.

Brown, T. A. (2006). Confirmatory factor analysis for applied research series. New York, NY: The Guilford Press.

Buyukozturk, S. (2013). Sosyal bilimler icin veri analizi el kitabi. (Manual of data analysis for social sciences) (23th ed.). Ankara, Turkey: Pegem Yayincilik.

Dere Ciftci, H. (2013). Iletisim becerileri. (Communication skills)(p. 7). Ankara, Turkey: Sage Yayincilik.

Elyildirim, S. (2019). Influence of native language and general English proficiency on the use of articles in English. Global Journal of Foreign Language Teaching, 9(2), 110-121. doi: 10.18844/gjflt.v9i2.4100 
Yıldız, F. Ü., Çağdaş, A. \& Kayılı G. (2020). BSSI-3 Spoken language, reading-writing forms: Validity and reliability study. Global Journal of Foreign Language Teaching. 10(3), 198-207. https://doi.org/10.18844/gjflt.v10i3.5074

Gander, M. J. \& Gardiner, H.W. (2017). Cocuk ve ergen gelisimi. (Child and adolescent development) (8. Baski., p.207) (Translation editor: Bekir Onur). Ankara, Turkey: Imge Yayinevi.

Hammill, D.D. Leigh, J. E., Pearson, N. A. \& Maddox, T. (1998). Basic school skills inventory-3 (3rd Ed.). Austin, TX: PRO-ED, Inc.

Johsnon, R. B. \& Christensen, L. (2014). Educational research quantitative, qualitative and mixed approaches (5th ed.). New York, NY: SagePub.

Karasar, N. (2013). Bilimsel arastirma yontemi. (Scientific research method) (27th ed.). Ankara, Turkey: Nobel Yayin Dagitim.

Kasten, H. (2017). 0-3 yas cocuk geilisimi \& Gelisim psikolojisinin temel esaslari (The basic principles of 0-3 age child development and developmental psychology) (Translation editor: Oguz Emre). Ankara, Turkey: AniYayincilik.

Kline, R. B. (2010). Principles and practice of structural equation modeling (3rd ed.). New York, NY: Guilford Press.

Mekkaoui, G. \& Mouhadjer, N. (2019). Addressing air traffic controllers' English language proficiency needs: case of Zenata airport. Global Journal of Foreign Language Teaching, 9(3), 167-183. doi: 10.18844/ gjflt.v9i3.4245

Montessori, M. (1997). Cocuk egitimi (The screet of childhood) (5. Baski), (Ceviren: Guler Yucel) (p. 52). Istanbul, Turkey: Ozgur Yayinevi.

Montessori, M. (2015a). Emici zihin (The absorbent mind) (Ceviren: Senem Bilgin) (p. 42). Istanbul, Turkey: Kaknus Yayinlari.

Montessori, M. (2015b). Cocuklugun sirri (The screet of childhood)(Ceviren: Okhan Gunduz) (p. 42). Istanbul, Turkey: Kaknus Yayinlari.

Namaziandost, E., Imani, A. \& Ziafar, M. (2020). An investigation of Iranian EFL teachers and learners' attitudes towards using language learning strategies. Global Journal of Foreign Language Teaching, 10(1), 65-71. doi:10.18844/gjflt.v10i1.4492

Ozdamar, K. (2004). Tablolarin olusturulmasi, guvenirlik ve soru analizi. paket programlarla istatistiksel veri analizi-1. (Creating tables, reliability and question analysis. Statistical data analysis with package programs-1) (5th ed., pp. 201-50, 621). Eskisehir, Turkey: Kaan Kitabevi.

Polk Lillard, P. (2013). Ilk ve ortaokulda montessori egitimi. (Montessori Today) (Ceviren: Okhan Gunduz). Istanbul, Turkey: Kaknus Yayinlari.

Senemoglu, N. (2013). Gelisim ogrenme ve ogretim: kuramdan uygulamaya. (Development learning and teaching: from theory to practice) (12ed.). Ankara, Turkey: Pegem Akademi.

Simsek, O. F. (2007). Yapisal esitlik modellemesine giris: temel ilkeler ve LISREL uygulamalari.(Introduction to structural equation modeling: basic principles and LISREL applications). Ankara, Turkey: Ekinoks.

Standing, E. M. (1998). Maria montessori, her life and work (s. 122). (With introduction by Lee Havis). New York, NY: Penguin Book Ltd.

Tezbasaran, A. A. (2008). Liikert tipi olcek hazirlama klavuzu (Likert type scale preparation guide) (3. Ed./ e kitap) Retrieved from https://www.academia.edu/1288035/Likert_Tipi_\%C3\%961\%C3\%A7ek_Haz\%C4\% B1rlama_K\%C4\%B1lavuzu (2019).

Wariyo, L. (2019). A instructional goal structure, gender and second language motivation affecting English language achievement. Global Journal of Foreign Language Teaching, 9(1), 69-81. doi:10.18844/ gjflt.v9i1.3137

Yavas Celik, G. \& Yavuz, F. (2020). The role of the language aptitude and self-reported strategy use on the achievement of EFL learners. Global Journal of Foreign Language Teaching, 10(1), 32-48. doi:10.18844/gjflt.v10i1.4412

Yildiz, F. U., Cagdas, A. \& Kayili, G. (2017). Basic school skills inventory-3: validity and reliability study. Journal of Education and Training Studies, 5(7), 28-36.Retrieved fromhttp://redfame.com/journal/index.php/ jets/article/viewFile/2485/2613(2019) 